JASEM ISSN 1119-8362

All rights reserved
Full-text Available Online at www.bioline.org.br/ja
J. Appl. Sci. Environ. Mgt. September, 2006

Vol. 10 (3) 157 - 158

\title{
Yeast Contamination Potential in a Carbonated Soft Drink Industry
}

\author{
*NWAIWU, O; IBEKWE, V I. \\ Department of Industrial Microbiology, School of Science, Federal University of Technology, Owerri, Imo State, \\ Nigeria.Email:guerinwaiwu@yahooo.co.uk; vibekwe1@yahoo.com Phone: 08037116539;08037111764.
}

\begin{abstract}
Components of the filling valve in a gravity filling machine namely, tulip rubber, spreader rubber and vent tube were analyzed for yeasts using the membrane filtration method. After 5 days incubation, it was found that the tulip rubber had the highest yeast count of $9 \mathrm{cfu} / 20 \mathrm{mls}$ while the vent tube had the least count of $5 \mathrm{cfu} / 20 \mathrm{mls}$. This indicates that the tulip rubber has the highest potential for contaminating finished products. Therefore, the tulip rubbers should be taken as a critical control point for control of yeast contamination during carbonated soft drink production.@JASEM
\end{abstract}

The organism most often called "yeast" such as common baking or brewing yeasts are strains of species of Saccharomyces cerevisiae (Thrall, 2004). Yeasts are useful in bakery and breweries but undesirable in carbonated soft drink industries due to their ability to ferment sugar (Nester et al. 1983). Sugar fermentation causes the product to change color and taste which results in a shorter shelf life (Anon, 1997).

If a carbonated soft drink manufacturer keeps the bottling environment yeast free, it shows that they are in control of the environment. It also indicates that safe and wholesome products are being produced (Nwaiwu and Ibekwe, 2003).

The purpose of this study was to identify the areas in a bottling line of a soft drink industry that has a high potential for yeast contamination.

\section{MATERIALS AND METHODS}

This study was carried out at the Nigerian Bottling Company, Owerri, and Imo State, Nigeria. Swab sticks were used to swab three filling valve components namely, tulip rubber, spreader rubber and vent tube after a production run. The swab sticks were then introduced into a test tube containing
$20 \mathrm{mls}$ of distilled water. It was left standing for 10 minutes after which the swab stick was discarded and the water filtered using a membrane filtration apparatus. Vacuum was applied to draw the sample through a 0.65 micron cellulose nitrate filter paper (Anon, 2002).

After filtration, the filter paper was placed on Schaufus pottinger media (Satorius) prepared according to manufacturers instruction and then incubated at $30^{\circ} \mathrm{C}$ for five days. Yeast colonies that emerged from the samples after three days incubation were counted, gram stained and morphological characteristics compared to yeast colonies described in Cheesebrough (1985).

\section{RESULTS AND DISCUSSION}

The yeasts isolated had some budding cells. The colonies were cream colored, ovoid, raised, and intact and were between 3-10 microns in diameter. They were also gram positive. These characteristics of the yeasts isolated are the same with that shown by Cheesebrough (1985). For all the samples there was no growth observed after 24 hours, but by the second day growth was seen in all the samples. After 5 days growth was highest in tulip rubber followed by spreader rubber and vent tube (Fig.1).

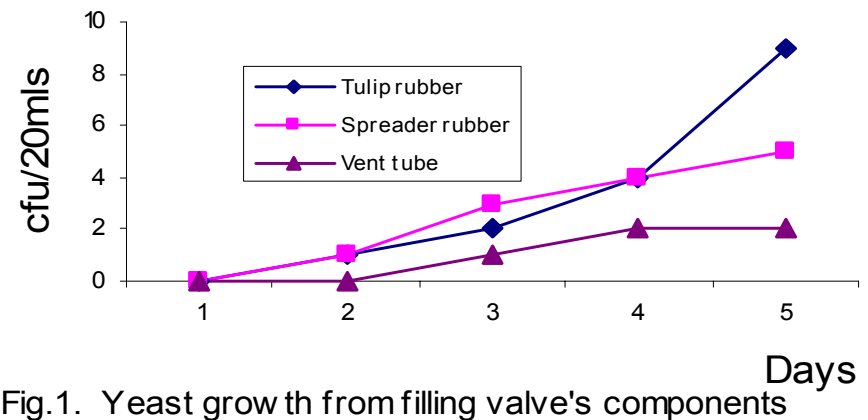

The structure and nature of the tulip rubber may have contributed in part to the highest growth observed for the tulip rubber. Unlike the vent tube and spreader rubber, tulip rubber is hollow (Anon, 2002) and may trap moisture and beverage which contains sugar.
This would provide favorable conditions for yeasts to ferment and proliferate.

Yeasts ability to ferment sugar has been reported severally (Jay, 1985; Beuchat, 1995). This ability to proliferate in the presence of sugar show that the 
yeasts isolated may be osmophillic yeasts. Osmophillic yeasts grow in areas of high sugar or salt concentration (Sipiczki, 2003).

Since the tulip rubber has the highest growth there is the need to pay close attention to it during sanitation of bottling equipment. It can be taken as a critical control point in other to monitor and prevent the proliferation of yeasts. It has been reported that the proper identification of critical control points is an important issue in the implementation of hazard analysis and critical control points (Dewettinck et al., 2001).

Knowing the critical control points would also ensure that as soon as yeast count is out of specification, a quick and sufficient corrective can be taken to prevent future occurrence. This would reduce risks of product contamination and also prove that the producers are in control of the environment.

\section{REFERENCES}

Anonymous (1997) Technical training manual. Nigerian Bottling Company PLC, Owerri, Nigeria.

Anonymous (2002) Membrane filtration and beverage sampling. Nigerian bottling company Plc Owerri. Doc No. OWWI-07-PR-MM-20-02.

Beuchat, L R (1995) Pathogenic organisms associated with fresh produce. J. Food Prot. 59: 204-216.

Cheesebrough, M (1985) Medical laboratory manual for tropical countries. (ELBS edition) Cambridgeshire and Butterworth publishers, Kent, UK. 478pp.
Dewettinck,T; Van Houtte,E; Geenens,D; Van Hege, K; Verstraete, W (2001) Water Science and Technology, 43(12) 31-38.

Jay, M J (1986) Modern Food Microbiology. $3^{\text {rd }}$ edition. CBS publishers India.

Nester, E N; Roberts, C E; Lidstrom, M E; Pearsall, N N; Nester, M T (1983) Microbiology $3^{\text {rd }}$

Edition. Saunders College Publishing,

Philadelphia. Pp. 66- 679.

Nwaiwu, O; Ibekwe, V I (2003) Determination of microbial load of surfaces through adenosine triphosphate bioluminescence. In: Proceedings of 27th Annual conference of the Nigerian Institute for Food Science

and Technology (NIFST). Kano, 13-17th October, 2003. Pp 92-93.

Sipiczki, M (2003) Candida zemplinina sp., an osmotolerant and psychrotolerant yeast that ferments sweet botrytized wines. Int J Syst Evol Microbiol, 53(6) 2079 - 2083.

Thrall, L (2004) Safety Management Services. Food Handler Inc.1thrall@foodhandler.com. 